\title{
A ozonização da água de unidades de tratamento odontológico e o controle microbiológico
}

\section{Water ozonization of dental treatment units and microbiological control}

\author{
Juliana Rico Pires ${ }^{1}$, Any Caroline Alves Barbosa ${ }^{1}$, Fabiano Sant'Ana dos Santos ${ }^{1}$, Elizângela Partata Zuza ${ }^{2}$ \\ ${ }^{1}$ Centro Universitário da Fundação Educacional de Barretos, UNIFEB, Barretos, SP, Brasil. \\ ${ }^{2}$ AUniversidade Federal Fluminense - UFF, Nova Friburgo/ Rio de Janeiro, Brasil.
}

\begin{abstract}
Resumo
As tubulações de água dos equipamentos odontológicos são consideradas focos de contaminação microbiana no consultório. O objetivo do presente estudo foi avaliar a efetividade antimicrobiana da ozonização da água de equipos odontológicos. Para tanto, um equipamento gerador de ozônio, fabricado por empresa nacional (Equipo Clean - Q2 TEC, Barretos, SP), foi acoplado ao sistema hidráulico de uma cadeira odontológica selecionada de forma aleatória, junto ao reservatório de água, próximo à caixa de comando. A água utilizada no reservatório do equipo odontológico foi proveniente do sistema de abastecimento de água do município. Foram coletadas, em seis momentos diferentes, amostras da água $(10 \mathrm{~mL})$ da seringa tríplice (ST), da cuspideira (CUS) e da saída do motor de alta rotação (AR) após 10 minutos da ozonização da água (grupo teste, $\mathrm{n}=6$ ). $\mathrm{O}$ grupo controle foi constituído de equipamentos odontológicos sem o gerador de ozônio $(n=6)$. A análise microbiológica foi feita por meio de identificação e contagem em unidades formadoras de colônia (UFC/mL) por meio da semeadura de cada amostra de água $(200 \mu \mathrm{L})$ em placas contendo meios de cultura específicos para crescimento de Escherichia coli, Staphylococcus aureus, coliformes totais, fungos e leveduras. As placas foram incubadas em estufa bacteriológica a $36^{\circ} \mathrm{C}$ por 24 horas. O grupo teste demonstrou redução estatisticamente significante da colonização microbiana das amostras das unidades de água dos equipamentos odontológicos testados quando comparado ao grupo controle (ANOVA, $\mathrm{p} \leq 0,05$ ). Conclui-se que a água ozonizada apresentou comprovada efetividade antimicrobiana, podendo ser utilizada no controle biológico do consultório odontológico.
\end{abstract}

Palavras-chave: ozônio; desinfetantes; antibacteriano; equipamento odontológico.

\begin{abstract}
Water pipes of dental equipment are considered sources of microbial contamination in dental offices. The objective of the this study is to evaluate the antimicrobial effectiveness of water ozonization on dental equipment. Thus, an ozone generator equipment manufactured by a Brazilian company (Equipo Clean-Q2 TEC, Barretos, SP) was coupled to the hydraulic system near the command box of a dental chair. The water used in the reservoir of the dental unit came from the public water supply system of the city. Water samples $(10 \mathrm{ml})$ of the triple syringe (TS), the spittoon (S) and high speed motor output (HSM) were collected after 10 minutes of water ozonization (test group, $n=6$ ) in 6 different periods. The control group was composed by water samples obtained from dental equipment without ozone generator $(\mathrm{n}=6)$. The microbiological analysis was performed by identification and counting of colony-forming units (cfu/mL) by seeding each water sample $(200 \mu \mathrm{L})$ on plates containing specific culture medium for Escherichia coli, Staphylococcus aureus, coliforms, fungus and yeasts. The plates were incubated in bacteriological greenhouse at $36^{\circ} \mathrm{C}$ for 24 hours. The ozonizated water showed statistically significant reduction of the microbial colonization
\end{abstract}

\footnotetext{
*Autor para correspondência: Juliana Rico Pires - Av. Roberto Frade Monte, 389, CEP14783-226, Barretos, SP, Brasil. Telefone (16) 997704669 - E-mail: juricopires@yahoo.com.br

Recebido em: 28/Out/2016
}

Aceito para publicação em: 03/Fev/2018

https://doi.org/10.4322/1980-0029.102016 
compared to the control group (ANOVA, $\mathrm{p} \leq 0.05$ ). It was concluded that the ozone generator was able to produce ozonizated water with antimicrobial properties which can be used in the biological control of dental offices.

Keywords: Ozone; Disinfectants; Anti-Bacterial Agents; Dental Equipment.

\section{Introdução}

Um dos grandes desafios enfrentados pela Odontologia atual é deter a propagação de infecções nos consultórios, as quais, pelo aumento da resistência dos microrganismos, pela falta de cuidado de alguns profissionais e pelo alto risco de transmissão de doenças infectocontagiosas, têm se intensificado (SCIAKY; SULITZEANU, 1962; FERREIRA, 1995; CLEGG, 1996; TEIXEIRA; SANTOS, 1999).

O Ministério da Saúde, por meio da Portaria $n^{\circ} 518 / 2004$, estabelece os procedimentos e as responsabilidades relativos ao controle e à vigilância da qualidade da água para consumo humano e seu padrão de potabilidade. Esse mesmo padrão é adotado na prática odontológica, uma vez que a água dos equipamentos odontológicos é colocada diretamente na cavidade bucal dos pacientes (BRASIL, 2004).

Estudos têm demonstrado que a água proveniente das unidades de tratamento odontológico apresenta grande potencial de contaminação entre o paciente e o cirurgião-dentista $\left(1 \times 10^{8} \mathrm{UFC} / \mathrm{mL}\right)$ (DHALEN; ALENAS-JARL; HJORT, 2009; NIKAEEN et al., 2009; PERCIVAL et al., 2009). Em função desse problema, a qualidade da água de abastecimento dos reservatórios dos equipamentos odontológicos utilizada durante procedimentos clínicos é causa constante de preocupação (COLEMAN et al., 2009; DHALEN; ALENAS-JARL; HJORT, 2009; NIKAEEN et al., 2009; PERCIVAL et al., 2009).

Alguns estudos têm evidenciado a contaminação microbiológica primária da água dos equipamentos odontológicos a partir da conexão com a rede de esgoto (SCIAKY; SULITZEANU, 1962; WILLIAMS et al., 1995). Autores acreditam que a contaminação secundária seja proveniente da mangueira/linha d'água, em virtude da formação de biofilme (WILLIAMS et al., 1993; WATANABE, 2003). Outros autores relacionam a contaminação da água dos equipamentos odontológicos ao refluxo da água, o que provoca a realimentação para o sistema e ocasiona a contaminação cruzada de outros pacientes (MILLS; KARPAY, 2002; COLEMAN et al., 2009). Adicionalmente, grande ênfase tem sido dada à alta rotação, pelo fato de 0 seu funcionamento de refrigeração levar à produção de aerossóis com alto potencial de contaminação do ambiente odontológico (BLAKE, 1963; FANTINATO et al., 1992; MILLS; KARPAY, 2002; WATANABE, 2003).

Entre as diversas técnicas de desinfecção dos equipamentos odontológicos testadas, alguns estudos indicam a utilização do gás ozônio $\left(\mathrm{O}_{3}\right)$, o qual vem demonstrando potencial oxidante superior ao do cloro no controle de infecção cruzada e no controle microbiológico em ambientes clínicos e cirúrgicos na área da saúde (BOCCI, 2000; FARIA et al., 2005; TERAO et al., 2003; JACINTO, 2012). O ozônio é utilizado na indústria alimentícia, no tratamento de água para reúso e de efluentes (GUZEL-SEYDIM; GREENE; SEYDIM, 2004) e na saúde das pessoas (BOCCI, 2005).

O ozônio também é empregado como substituto do cloro, demonstrando eficácia na inativação de bactérias, vírus e protozoários (COSTA; DANIEL, 2002) e na destruição do biofilme, podendo causar descontaminação de superfícies de contato de equipamentos e em circuitos hidráulicos (KIM; YOUSEF; DAVE, 1999; DHALEN; ALENASJARL; HJORT, 2009).

O ozônio exerce forte efeito germicida devido ao seu alto potencial oxidante dos elementos que constituem as paredes celulares, penetrando, assim, no interior dos microrganismos e oxidando enzimas, proteínas e ácidos nucleicos, o que leva à destruição e à morte da célula microbiana (AGUIAR; PINHEIRO, 1999; BOCCI, 2000, 2005; MAHAPATRA; MUTHUKUMARAPPAN; JULSON, 2005).

A utilização da água ozonizada com o objetivo de minimizar a presença de contaminação nas linhas de água foi empregada em diferentes estudos não padronizados, os quais demonstraram eficiente ação desinfetante do ozônio (RICE et al., 1981; JÁNNUZZI, 1991; VELANO et al., 2001; COSTA; DANIEL, 2002; TERAO et al., 2003; FARIA et al., 2005; MAHAPATRA; MUTHUKUMARAPPAN; JULSON, 2005). 
A hipótese nula é comprovar que a água ozonizada obtida pelo gerador de ozônio tem ação desinfetante e/ou antimicrobiana, demonstrada pela redução da carga microbiana das unidades de água dos equipamentos odontológicos.

O objetivo do presente estudo foi avaliar a efetividade antimicrobiana da ozonização da água de equipos odontológicos por meio da utilização de equipamento fabricado por empresa nacional (Equipo Clean - Q2 TEC, Barretos, SP).
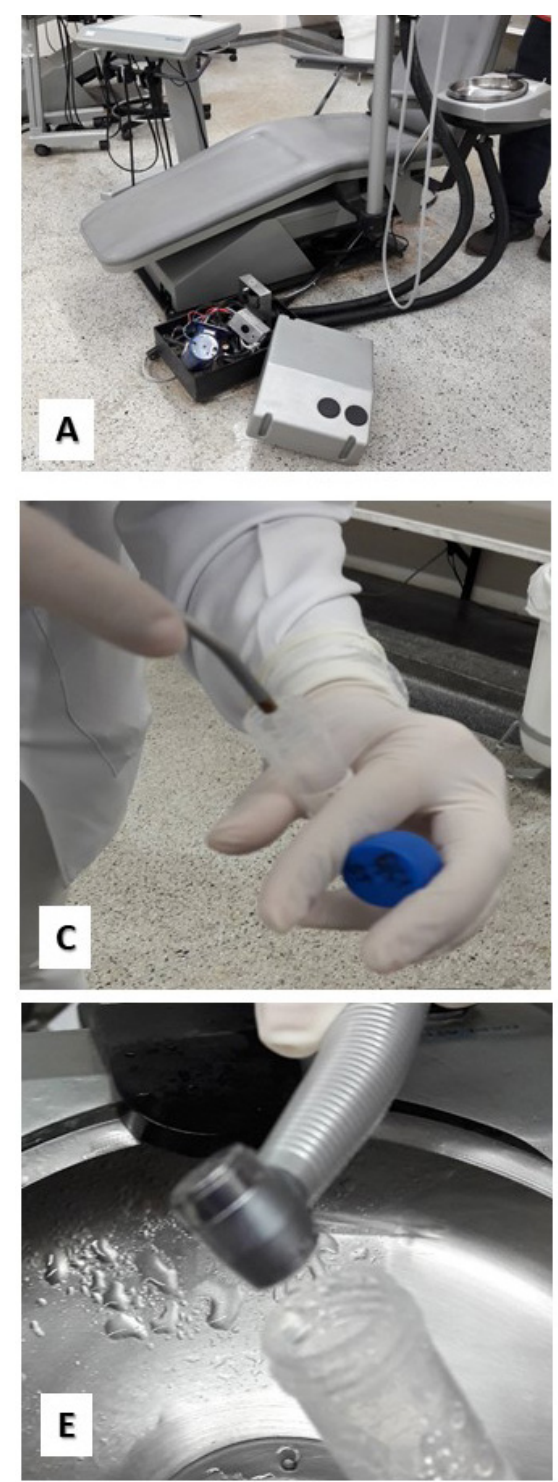

\section{Material e Métodos}

\section{Instalação do equipamento gerador de ozônio}

Os equipamentos fabricados por empresa nacional (Equipo Clean - Q2 TEC, Barretos, SP) foram acoplados ao sistema hidráulico da cadeira, junto ao reservatório de água, próximo à caixa de comando de um equipo selecionado de forma aleatória (grupo teste), na Clínica Integrada do
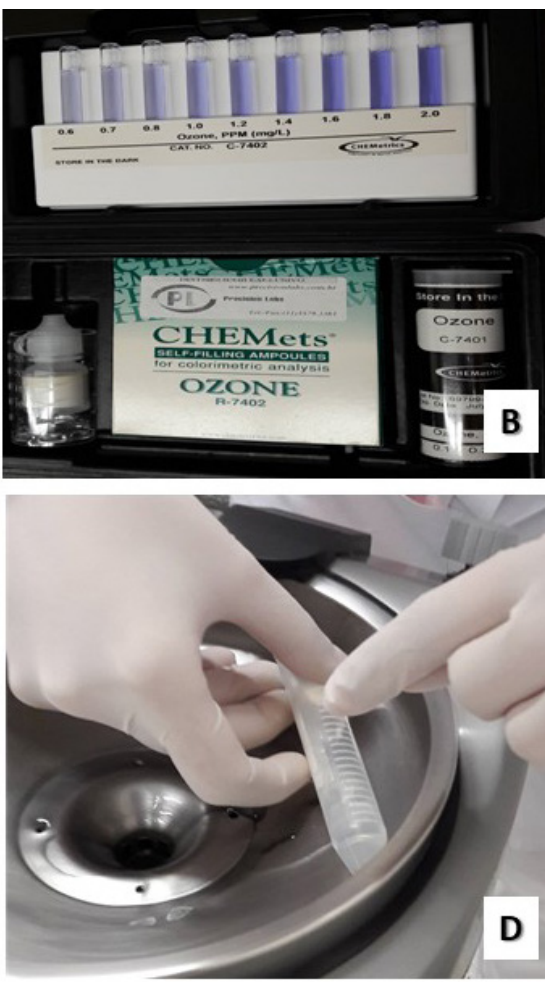

D

Figura 1. A. Equipamento acoplado ao sistema hidráulico da cadeira odontológica. B. Kit para teste de concentração ozônio. C. Coleta das amostras de água da Seringa Tríplice (ST) em tubos de falcon estéreis. D. Coleta das amostras de água da Cuspideira (CUS) em tubos de falcon estéreis. E. Coleta das amostras de água do motor de Alta Rotação (AR) em tubos de falcon estéreis. 
Centro Universitário da Fundação Educacional de Barretos (UNIFEB) (Figura 1A).

A água utilizada no reservatório do equipo odontológico foi proveniente do sistema de abastecimento de água do município. A concentração final da água ozonizada foi analisada por meio do teste de concentração, com ampolas que, comparadas em uma escala colorimétrica, identificavam a concentração de ozônio presente na água (CHEmets kit ozone) (Figura 1B). Obteve-se a concentração final da água coletada na seringa tríplice (ST), na cuspideira (CUS) e no motor de alta rotação (AR).

O kit utilizado para os testes de concentração são da marca CHEmets, contendo material necessário para realização 30 testes: ampolas, escalas colorimétrica de baixa (0,1-0,5 PPM mg/L) e alta (0,6-2,0 PPM mg/L) concentração, solução ativadora e copo de $25 \mathrm{~mL}$ para amostras. Adicionaram-se 5 gotas de solução ativadora no copo de $2 \mathrm{~mL}$ e, em seguida, $25 \mathrm{~mL}$ de amostra de água proveniente de cada local (ST, CUS e AR). Imediatamente após a coleta, colocou-se uma ampola em posição no copo de $25 \mathrm{~mL}$ com a amostra de água e quebrou-se sua ponta dentro do copo; então, a ampola logo encheu de água da amostra coletada. Misturou-se, invertendo várias vezes a ampola, e secou-se durante 1 minuto para desenvolvimento da cor. Obteve-se um resultado para cada amostra, o qual foi analisado usando a escala apropriada (baixa ou alta concentração).

\section{Preparação do material para coleta das amostras}

As placas de petri tiveram suas tampas revestidas com discos de papel-filtro qualitativas (Nalgon). Após esse procedimento, foram embrulhadas em papel-manteiga e colocadas em bandejas; assim, foram esterilizadas.

Previamente à análise microbiológica, foi feita a preparação dos meios de cultura para identificação dos microrganismos: Escherichia coli (E.coli), Staphylococcus aureus (S.aureus), coliformes totais, fungos e leveduras.

Para E.coli e coliformes totais, utilizou-se o meio de cultura EMB (Eosina Azul de Metileno Levine Agar) da marca Kasvi. Foram dissolvidas 37,5 gramas de meio de cultura em $1.000 \mathrm{~mL}$ (1 L) de água destilada e então misturadas até sua completa dissolução, com esterilização em autoclave a $121^{\circ} \mathrm{C}$ por 15 minutos
Para S. aureus, utilizou-se o meio de cultura MH (Mueller Hinton Agar) da marca Himedia. Foram dissolvidas 38 gramas de meio de cultura em $1.000 \mathrm{~mL}(1 \mathrm{~L})$ de água destilada e agitadas até completa dissolução do meio, com esterilização em autoclave a $121^{\circ} \mathrm{C}$ por 15 minutos e agitação após a autoclave. Também utilizou-se para $S$. aureus o meio de cultura DNAase (DNAase Test Agar Base) da marca Himedia. Foram dissolvidas 42 gramas de meio de cultura em $1.000 \mathrm{~mL}(1 \mathrm{~L})$ em água destilada, com frequente agitação até dissolução completa e esterilização na autoclave a $121^{\circ} \mathrm{C}$ por 15 minutos.

Para fungos e leveduras, foi utilizado o meio de cultura SA (Agar Sabouraud Dextrosado) da marca Prodimol Biotecnologia. Foram dissolvidas 65 gramas de meio de cultura em $1.000 \mathrm{~mL}(1 \mathrm{~L})$ de água destilada, aquecidas, fervidas e agitadas frequentemente por 1 minuto para completa dissolução do meio. Logo após, esse procedimento foi autoclavado.

Após o preparo de todos os meios de culturas, foram distribuídos $20 \mathrm{~mL}$ por placa de petri e armazenados em estufa bacteriológica a $36{ }^{\circ} \mathrm{C}$ por 24 horas para posterior uso dos meios.

\section{Obtenção das amostras}

As amostras de água foram coletadas em tubos tipo Falcon estéreis para posterior análise microbiológica. Amostras da água $(10 \mathrm{~mL}) \mathrm{da}$ seringa tríplice (ST) (Figura 1C), da cuspideira (CUS) (Figura 1D) e da saída do motor de alta rotação (AR) (Figura 1E) foram obtidas após 10 minutos do início da ozonização da água com o equipamento (grupo teste).

Esse procedimento foi repetido seis vezes. Dessa forma, foram obtidas seis amostras de água ( $5 \mathrm{~mL}$ ) de cada local (ST, CUS e AR). Da mesma forma, foi realizada a coleta em seis equipamentos odontológicos sem o gerador de ozônio (grupo controle).

Algumas placas com meio de cultura universal (MH) foram dispostas com $1 \mathrm{~m}$ de distância ao redor das cadeiras odontológicas, sendo esse procedimento realizado na cadeira odontológica com gerador de ozônio utilizada para a coleta do grupo teste e na cadeira odontológica utilizada para as coletas do grupo controle.

Essas placas foram abertas no período da manhã, quando se inicia a clínica Integrada do Centro Universitário da Fundação Educacional de Barretos (UNIFEB), e ficaram expostas pelo período de 
1 hora. Após esse procedimento, as placas foram levadas ao laboratório de microbiologia, incubadas em estufa bacteriológica $36 \%$ por 24 horas, e, em seguida, foi realizada a análise microbiológica, fazendo a contagem do crescimento bacteriano $\mathrm{em} \mathrm{UFC/mL.}$

\section{Análise microbiológica}

A análise microbiológica foi feita por meio de identificação e contagem em unidades formadoras de colônia (UFC/mL) por meio da semeadura de cada amostra em placas de identificação com meios de cultura específicos para os microrganismos: Escherichia coli, Staphylococcus aureus, coliformes totais, fungos e leveduras.

Para tanto, no fluxo laminar, após vibração constante (Vortex), $200 \mu \mathrm{L}$ de cada amostra foram plaqueadas nos meios de cultura específicos.

As placas foram incubadas em estufa bacteriológica a $36{ }^{\circ} \mathrm{C}$ por 24 horas.

Após esse tempo, foi observada presença ou ausência do crescimento das colônias com auxílio de uma lupa estereoscópica. Confirmado o crescimento, foi realizada a contagem em unidades formadoras de colônias (UFC/mL) por meio de um contador de células.

Cada meio apresenta suas próprias características. A cor original do meio EMB é vermelho-escuro com tom esverdeado, mas quando apresenta colônias preto-azuladas são coliformes fecais. Colônias com brilho verde metálico são fermentadoras de lactose, enquanto colônias incolores são não fermentadoras de lactose.

A cor original do MH é amarela-palha, mas quando há presença de microrganismo ela se apresenta opaca e ocorre a formação de um halo de crescimento.
A cor original do meio SA é amarelo-claro opalescente, mas, após o crescimento de fungos e leveduras, deve seguir a identificação quando da formação do halo de crescimento opaco.

A cor original do meio de cultura DNAase com azul de toluidina é azul, quando ocorre o crescimento de Staphylococcus sp que possui a enzima desoxirribonuclease, causando a degradação do ácido nucleico (DNA) e formando o halo cor-de-rosa ao redor do inóculo, o que indica a presença dessa bactéria.

\section{Análise estatística}

Os resultados em UFC/mL foram convertidos para logaritmo e submetidos à análise estatística ANOVA (Tukey) para $\mathrm{p} \leq 0,05$.

\section{Resultados}

Inicialmente, a água utilizada no reservatório do equipo odontológico, proveniente do sistema de abastecimento de água do município, foi analisada por meio do teste de concentração de ozônio presente na água (CHEmets kit ozone). Obteve-se a concentração final da água coletada na seringa tríplice (ST), na cuspideira (CUS) e no motor de alta rotação (AR). A concentração final de ozônio das amostras de água coletadas na seringa tríplice (ST) apresentou 0,6 PPM $(\mathrm{mg} / \mathrm{L})$; na cuspideira (CUS), as amostras apresentaram 1,3 PPM (mg/L); no motor de alta rotação, as amostras apresentaram 1,2 PPM (mg/L).

Os resultados podem ser observados na Tabela 1, na qual existe a presença de diferença estatisticamente significante entre os grupos testados. Aágua ozonizada gerada pelo equipamento (Equipo Clean - Q2 TEC, Barretos, SP) é capaz

Tabela 1. Colonização microbiana nas áreas coletadas nos grupos testados (UFC/mL) na casa decimal de $10^{2}$.

\begin{tabular}{|c|c|c|c|c|c|}
\hline \multirow[b]{2}{*}{ Áreas de coleta } & \multirow[b]{2}{*}{ Grupos } & \multicolumn{4}{|c|}{ Meios de cultura $\left(\times 10^{2}\right)$} \\
\hline & & $\begin{array}{c}\text { MH } \\
\text { média } \pm \text { DP }\end{array}$ & $\begin{array}{c}\text { SA } \\
\text { média } \pm \mathbf{D P}\end{array}$ & $\begin{array}{c}\text { DNAase } \\
\text { média } \pm \text { DP }\end{array}$ & $\begin{array}{c}\text { BEM } \\
\text { média } \pm \text { DP }\end{array}$ \\
\hline \multirow[t]{2}{*}{ CUS } & Teste & $1,0 \pm 1,2^{\alpha}$ & $3,2 \pm 4,0^{\alpha}$ & $6,8 \pm 4,6^{\alpha}$ & $2,0 \pm 1,8^{\alpha}$ \\
\hline & controle & $9,7 \pm 1,8$ & $27,5 \pm 9,4$ & $48,2 \pm 20,4$ & $43,7 \pm 11,1$ \\
\hline \multirow[t]{2}{*}{$\mathbf{A R}$} & Teste & $9,0 \pm 2,2^{\alpha}$ & $4,2 \pm 1,2$ & $3,4 \pm 1,6^{\alpha}$ & $0 \pm 0^{\alpha}$ \\
\hline & controle & $38,0 \pm 9,2$ & $7,0 \pm 3,7$ & $37,2 \pm 10,2$ & $23,0 \pm 11,2$ \\
\hline \multirow[t]{2}{*}{ ST } & Teste & $3,0 \pm 4,1^{\alpha}$ & $2,5 \pm 3,3^{\alpha}$ & $4,2 \pm 3,1^{\alpha}$ & $0 \pm 0^{\alpha}$ \\
\hline & controle & $47,2 \pm 7,1$ & $45,7 \pm 4,6$ & $35,0 \pm 3,5$ & $20,5 \pm 2,8$ \\
\hline
\end{tabular}

CUS = cuspideira; $\mathrm{AR}$ = alta rotação; $\mathrm{ST}$ = seringa tríplice; $\mathrm{UFC}=$ unidade formadora de colônia; $\mathrm{DP}$ = desvio-padrão; $\mathrm{MH}=$ Mueller Hinton Agar; SA = Agar Sabouraud Dextrosado; DNAase = DNAase Test Agar Base; EMB = Eosina Azul de Metileno Levine Agar. ${ }^{a}$ Símbolos significam presença de diferença estatisticamente significante entre os grupos para a área de coleta correspondente e para cada meio de cultura utilizado, pelo teste ANOVA (Tukey $\mathrm{p} \leq 0,05$ ). 
Tabela 2. Teste para verificação de contaminação no ambiente.

\begin{tabular}{cc}
\hline Grupos & $\begin{array}{c}\text { Número de colônias (UFC/mL) } \\
\text { Média } \pm \text { DP }\end{array}$ \\
\hline Teste & $21,0 \pm 4,0^{\alpha}$ \\
controle & $57,5 \pm 17,0$ \\
\hline
\end{tabular}

* UFC = unidade formadora de colônia; $\mathrm{DP}=$ desvio-padrão.

${ }^{\alpha}$ Símbolos significam presença de diferença estatisticamente significante entre os grupos para a área de coleta correspondente e para cada meio de cultura utilizado, pelo teste ANOVA (Tukey $\mathrm{p} \leq 0,05$ ).

de diminuir a colonização microbiana das áreas coletadas.

Como é possível observar na Tabela 2 , verificou-se uma diminuição de $50 \%$ na contaminação do ambiente em $1 \mathrm{~m}$ de diâmetro da cadeira odontológica com a utilização do gerador de ozônio quando comparado ao grupo controle $\left(21 \times 10^{2}\right.$ e $54,5 \times 10^{2}$, respectivamente).

\section{Discussão}

Os resultados demonstraram a efetividade antimicrobiana da ozonização da água de equipos odontológicos por meio da utilização de equipamento fabricado por empresa nacional (Equipo Clean - Q2 TEC, Barretos, SP). A redução microbiana observada após ozonização da água de abastecimento do equipamento odontológico em comparação ao grupo controle está em concordância com estudos que relataram que o ozônio tem sido utilizado como substituto do cloro, demonstrando eficácia na inativação de bactérias, vírus e protozoários (COSTA; DANIEL, 2002; LOPES et al., 2013) e na destruição do biofilme, podendo ser utilizado na descontaminação de superfícies de contato de equipamentos e em circuitos hidráulicos (KIM; YOUSEF; DAVE, 1999; DHALEN; ALENASJARL; HJORT, 2009).

A presença de contaminação na água que abastece a unidade de tratamento odontológico, associada a um possível refluxo de fluídos do meio bucal para o sistema, permite a circulação de microrganismos patogênicos nas mangueiras das linhas d'água, possibilitando sua adesão e formação de biofilme nas paredes internas (JACINTO, 2012). Tal fato pode ser justificado pela presença de microrganismos nas amostras de água coletadas da cuspideira, do motor de alta rotação e da seringa tríplice no grupo controle.
Salienta-se que, após 10 minutos de acionamento do gerador de ozônio, foi possível verificar redução da microbiota encontrada nas amostras de água. A ozonização apresenta eficiência para o controle microbiológico, indicando redução do número de $\mathrm{UFC} / \mathrm{mL}$ encontrado na água após a sua saída (JACINTO, 2012). Tais achados estão em concordância com os resultados de outros autores, que demonstraram que a utilização da água ozonizada minimiza a presença de contaminação nas linhas de d'água (RICE et al., 1981; JANNUZZI, 1991; VELANO et al., 2001; FARIA et al., 2005; MAHAPATRA; MUTHUKUMARAPPAN; JULSON, 2005). Ademais, apesar de não apresentarem uma padronização de protocolos de concentração, tempo e frequência, mostraram uma eficiente ação desinfetante de ozônio devido ao seu alto poder de oxirredução.

No teste de verificação de contaminação no ambiente, foi possível verificar uma diminuição de $50 \%$ na contaminação em $1 \mathrm{~m}$ de diâmetro da cadeira odontológica com a utilização do gerador de ozônio. Diante desses achados, pode-se dizer que a água ozonizada é uma opção no controle da infecção cruzada odontológica, visto que o ozônio exerce potente efeito germicida em razão do seu alto potencial oxidante dos elementos que constituem as paredes celulares, penetrando, assim, no interior dos microrganismos e oxidando enzimas, proteínas e ácidos nucleicos, o que leva à destruição e à morte da célula microbiana (AGUIAR; PINHEIRO, 1999; BOCCI, 2000, 2005; MAHAPATRA; MUTHUKUMARAPPAN; JULSON, 2005).

Acredita-se que a comprovação da efetividade da água ozonizada como agente desinfetante traz benefícios adicionais no controle da infecção cruzada na clínica odontológica por ser uma substância de rápida obtenção e de fácil aplicação.

\section{Conclusão}

Conclui-se que a água ozonizada apresentou comprovada efetividade antimicrobiana, podendo ser utilizada no controle biológico do consultório odontológico.

\section{Agradecimentos}

À Empresa Q2Tec pelo apoio financeiro por meio do fornecimento do equipamento gerador de ozônio e por toda assistência técnica para instalação, utilização e manutenção do equipamento. 


\section{Referências}

AGUIAR, C. M.; PINHEIRO, J. T. Avaliação bacteriológica da qualidade da água utilizada nos equipos odontológicos. Revista da Associação Paulista de Cirurgiões Dentistas, v. 53, n. 3, p. 228-235, 1999.

BLAKE, G. C. The incidence and control of bacterial infection in dental spray reservoirs. British Dental Journal, v. 115, n. 11, p. 413-446, 1963.

BOCCI, V. Ossigeno ozonoterapia: compresione dei mecanismi di ozone e passibilita terapeutiche. Milano: Ambrosiana, 2000. 347 p.

BOCCI, V. Ozone: a new medical drug. 1. ed. Dordrecht: Springer, 2005. 299 p.

BRASIL. Ministério da Saúde. Portaria n ${ }^{\circ}$ 518/2004: legislação federal sobre controle e vigilância da qualidade da água para consumo humano e seu padrão de potabilidade. Brasília, 2004.

CLEGG, M. Dental unit waterlines in media spotlight. Comuniquè, v. 12, p. 3, 1996.

COLEMAN, D. C. et al. Biofilm problems in dental unit water systems and its practical control. Journal of Applied Microbiology, v. 106, n. 5, p. 1424-1437, 2009. http://dx.doi.org/10.1111/j.13652672.2008.04100.x.

COSTA, H.; DANIEL, L. Estudo do comportamento do ozônio na desinfecção de águas residuárias domiciliares. [S.1.: s.n.], 2002. PROSAB Edital 3.

DHALEN, G.; ALENAS-JARL, E.; HJORT, G. Water quality in water lines of dental units in the public dental health servisse in Goteborg, Sweden. Swedish Dental Journal, v. 33, n. 4, p. 161-172, 2009.

FANTINATO, V. et al. Exame bacteriológico da água em clínica odontológica. Revista da Associação Paulista de Cirurgiões Dentistas, v. 46, n. 4, p. 829-831, 1992.

FARIA, S. I. et al. Effects of ozonated water on Candida albicans oral isolates brazilian. Journal of Science, v. 4, n. 14, p. 783-786, 2005.

FERREIRA, R. A. Barrando o invisível. Revista da Associação Paulista de Cirurgiões Dentistas, v. 49, n. 6, p. 417-427, 1995.
GUZEL-SEYDIM, Z. B.; GREENE, A. K.; SEYDIM, A. C. Use of ozone in food industry. Lebensmittel-Wissenschaft + Technologie, v. 37, n. 4, p. 453-460, 2004. http://dx.doi.org/10.1016/j. lwt.2003.10.014.

JACINTO, R. B. S. Ozonização para controle microbiológico de linhas d'água em equipos odontológicos. 61 f. Dissertação (Mestrado) Faculdade de Engenharia Biomédica, Universidade Federal de São Paulo, São José dos Campos, 2012.

JÁNNUZZI, H. Ozone in water treatment cooperative research report. Mar del Plata: Grupo FG, 1991. Disponível em: $<\mathrm{http}: / / \mathrm{www}$.fgingenieria.com. ar>. Acesso em: 28 out. 2016.

KIM, J.-G.; YOUSEF, A.; DAVE, S. Application of ozone for enhancing the microbiological safety and quality of foods: a review. Journal of Food Protection, v. 62, n. 9, p. 1071-1087, 1999. http:// dx.doi.org/10.4315/0362-028X-62.9.1071.

LOPES, W. R. R.; OLIVEIRA, R. M. S.; SERRA, J. C. V. Avaliação comparativa entre os métodos de desinfecção empregando cloro e ozônio de águas destinadas ao abastecimento de pequenas comunidades. Fórum Ambiental da Alta Paulista. v. 9, n. 11, p. 463-472, 2013.

MAHAPATRA,A. K.; MUTHUKUMARAPPAN, K.; JULSON, J. L. Appliation of ozone, bactericides and radiation in food processing: a review critical. Food Science \& Nutrition, v. 45, n. 6, p. 447-461, 2005.

MILLS, S. E.; KARPAY, R. I. Dental waterline and biofilm: searching for solutions. Compendium of Continuing Education in Dentistry, v. 23, p. 237-258, 2002.

NIKAEEN, M. et al. Microbial quality of water in dental units waterlines. Journal of Research in Medical Sciences, v. 14, n. 5, p. 297-300, 2009.

PERCIVAL, R. S. et al. Controlo f microbial contamination in dental unit water systems using tetra-sodyum EDTA. Journal of Applied Microbiology, v. 107, n. 4, p. 1081-1088, 2009. http://dx.doi.org/10.1111/j.1365-2672.2009.04299.x.

RICE, J. O. et al. Uses of ozone in drinking water treatment. Journal - American Water Works 
Association, v. 73, n. 1, p. 44-57, 1981. http:// dx.doi.org/10.1002/j.1551-8833.1981.tb04637.x.

SCIAKY, I.; SULITZEANU, A. Importance of dental units in the mechanical transfer of oral bacteria. Journal of Dental Research, v. 41, n. 7, p. 714, 1962. http://dx.doi.org/10.1177/0022034 5620410032701.

TEIXEIRA, M.; SANTOS, M. V. Responsabilidade no controle de infecção. Revista da Associação Paulista de Cirurgiões Dentistas, v. 53, n. 3, p. 177-189, 1999.

TERAO, R. et al. Technical note: $100 \%$ ozonetreatment system of bath water. Ozone Science and Engineering, v. 25, n. 4, p. 345-349, 2003. http://dx.doi.org/10.1080/01919510390481667.

VELANO, H. E. et al. Avaliação in vitro da atividade antibacteriana da água ozonizada frente ao Staphylococcus aureus. Pesquisa Odontologica Brasileira, v. 15, n. 1, p. 18-22, 2001.

WATANABE, E. Avaliação de níveis de contaminação da água de equipos odontológicos. Dissertação (Mestrado) - Faculdade de Ciências Farmacêuticas, Universidade de São Paulo, Ribeirão Preto, 2003.

WILLIAMS, H. N. et al. Bacterial contamination of the water supply in newly installed dental units. Quintessence International, v. 26, n. 5, p. 331-337, 1995.

WILLIAMS, J. F. et al. Microbial contamination of dental unit waterlines: prevalence, intensity and microbiological characteristics. The Journal of the American Dental Association, v. 124, n. 10, p. 59-65, 1993. http://dx.doi.org/10.14219/jada. archive.1993.0205. 